\title{
Potential of High Compressive Ductility of Ultrafine Grained Copper Fabricated by Severe Plastic Deformation
}

\author{
Mayu Asano ${ }^{1}$, Motohiro Yuasa ${ }^{1}$, Hiroyuki Miyamoto ${ }^{1, *} \mathbb{(}$, Tatsuya Tanaka ${ }^{1}$, Can Erdogan ${ }^{2} \mathbb{C}$ \\ and Tuncay Yalçinkaya 2 (D) \\ 1 Department of Mechanical Engineering, Doshisha University, Kyoto 619-0394, Japan; \\ cyjc1501@mail4.doshisha.ac.jp (M.A.); myuasa@mail.doshisha.ac.jp (M.Y.); \\ tatanaka@mail.doshisha.ac.jp (T.T.) \\ 2 Department of Aerospace Engineering, Middle East Technical University, Ankara 06800, Turkey; \\ cane@metu.edu.tr (C.E.); yalcinka@metu.edu.tr (T.Y.) \\ * Correspondence: hmiyamot@mail.doshisha.ac.jp; Tel.: +81-0774-65-6406
}

Received: 10 October 2020; Accepted: 9 November 2020; Published: 11 November 2020

\begin{abstract}
Severe plastic deformation (SPD) can fabricate high-strength materials by forming an ultrafine grained (UFG) microstructure. Low elongation to failure of UFG materials in tensile tests, which has often been regarded as a measure of ductility of materials, has been attributed to low strain hardening of UFG structures where dislocation slip and its accumulation is very limited. In the present work, it is shown that the compressive extensibility of UFG materials can be comparable or potentially superior to that of annealed materials by using a parallel round-bar compression (PRBC) test which was designed for imposing an appropriate stress state preferable for high ductility using the shear mode. The high compressive extensibility of UFG materials can be a result of high accommodation of local strain incompatibility at non-equilibrium grain boundaries and a grain boundary-mediated deformation mechanism, which result in high damage tolerance against void formation and growth. Low strain rate sensitivity indicated that the superplastic viscous nature of deformation is not involved in the high compressive ductility of UFG materials using SPD.
\end{abstract}

Keywords: severe plastic deformation; equal-channel angular pressing; ductility; ultrafine grained structure; compression test

\section{Introduction}

Severe plastic deformation (SPD), which is represented by equal-channel angular pressing (ECAP), accumulative roll bonding (ARB) and high-pressure torsion (HPT), can fabricate bulk ultrafine grained (UFG) metallic materials. Since SPD emerged in the 1980s, a broad spectrum of materials has been deformed using SPD [1]. Among these materials, pure copper is one of the most investigated model materials to investigate microstructure evolution [2,3], mechanical properties [4], corrosion properties [5,6] and develop new types of SPDs [7-10].

Strength and ductility are important properties of materials for load-carrying structural applications. However, strengthening by manipulating the microstructure often compromises ductility. As in traditional high-strength structural materials, this strength-ductility trade-off has been an important issue in nanostructured and UFG materials fabricated using SPD ever since the advent of SPD [11-15]. In the context of strength-ductility, ductility seems to represent the ability of tensile elongation to failure. Thus, in general, ductility is evaluated using tensile tests as the total elongation to failure. In this method, the elongation can be divided into the uniform and local elongation, the former is elongation prior to the onset of necking and the latter is the post-necking elongation localized in 
the necking. Uniform elongation is often regarded as more important than the other type because it is associated with formability in many deformation modes. Reduction of uniform elongation via strengthening is usually associated with a loss of strain-hardening capability which is caused by limited mobility and accumulation of dislocations. According to Considere's criterion [16], $\sigma=\mathrm{d} \sigma / \mathrm{d} \varepsilon$, where $\sigma$ and $\varepsilon$ are true stress and true strain, respectively, uniform strain at the onset of necking is equal to $n$, where $n$ is called the strain-hardening exponent, and when the flow stress follows the parabolic-hardening law, $\sigma=K \varepsilon^{n}$. Most strategies to overcome the strength-ductility trade-off are concerned with enhancing the strain-hardening component [12]. On the other hand, several papers reported that UFG materials have high post-necking ductility in spite of high yield stress and low strain hardening $[11,15,17]$, and this can be attributed to its unique deformation mechanism accompanying grain boundary sliding and grain rotations at room temperature, frequently referred to as grain boundary-mediated plasticity [11]. This grain boundary sliding and rotation are considered to be facilitated by non-equilibrium grain boundaries generated by intense plastic strain [11].

Ductility is very sensitive to a material's microstructure such as the second phase, grain size, as well as the external state, i.e., flow mode and stress triaxiality, $\sigma_{\mathrm{m}} / \sigma_{\text {eq }}$, defined as

$$
\begin{gathered}
\sigma_{\mathrm{m}}=\frac{1}{3}\left(\sigma_{1}+\sigma_{2}+\sigma_{3}\right) \\
\sigma_{\mathrm{eq}}=\sqrt{\frac{1}{2}\left[\left(\sigma_{1}-\sigma_{2}\right)^{2}+\left(\sigma_{2}-\sigma_{3}\right)^{2}+\left(\sigma_{3}-\sigma_{1}\right)^{2}\right]}
\end{gathered}
$$

where $\sigma_{1}, \sigma_{2}$, and $\sigma_{3}$ denote principal stress. Ductility generally increases at lower stress triaxiality with compressive stress when void growth and connection is the fracture process [18]. Because of the unique deformation mode of UFG materials, the effect of triaxiality stress on ductility could be stronger in UFG materials using ECAP than the coarse-grained materials [19].

Considering the deformation mechanism of UFG materials, which proceeds by grain boundary sliding with little or no strain hardening, one can expect high ductility (maximum strain of any form to fracture) under a compressive stress state if void nucleation and growth can be suppressed by an appropriate stress state [20]. In addition to tensile tests, compression tests have been employed to examine the mechanical behavior of UFG materials [21-29]. Compared with tensile tests, compression tests allow us to examine the stress-strain relation in larger strain ranges because the test is not interrupted by the onset of necking. For UFG materials, the necking starts to form at very small strain in tensile tests so that one cannot examine the stress-strain behavior. To date, compression tests have been utilized to clarify the strain-hardening behavior [21,25,26,29] and deformation kinetics $[22,24,27,28]$. However, evaluating compressive ductility using general compression tests has been limited to hard or brittle materials.

It is practically and scientifically important to clarify the effect of deformation mode, or stress state, on ductility using various stress states in order to explore the processing preferable for UFG materials using SPD. In the present study, as a first step of this long-term study for the above purpose, a special compression test using parallel cylindrical bars was invented to evaluate an extreme ductility under compressive mode (malleability). This approach enables us to compress the samples to extremely small thickness with high precision with a comparatively lower compressive load. The high malleability of UFG materials using SPD in comparison with as-annealed materials is demonstrated in the present study and is attributed to high damage tolerance by the deformation mechanism under a compressive stress state $[30,31]$.

\section{Materials and Methods}

Copper billets of commercial purity with rectangular cross section $(8 \mathrm{~mm} \times 8 \mathrm{~mm})$ and length of $100 \mathrm{~mm}$ were pressed using ECAP for eight passes. Prior to ECAP, the billets were annealed at $873 \mathrm{~K}$ for $1 \mathrm{~h}$ to obtain a homogeneous microstructure. ECAP was carried out using a die with a channel 
angle of $90^{\circ}$ at room temperature at a pressing speed of $10 \mathrm{~mm} / \mathrm{min}$. The billets were rotated around its longitudinal axis between each pass according to the so-called route Bc. Tensile tests were performed to examine the strain hardening behavior and ductility after ECAP using an automated universal tensile test machine AGX-X (Shimadzu, Kyoto, Japan). Since the tensile test sample and its gauge part is small $(2 \mathrm{~mm} \times 2 \mathrm{~mm} \times 10 \mathrm{~mm})$, due to the limitation of the ECAP billet size, strain was measured using a non-contact digital video extensometer TRViewX (Shimadzu, Kyoto, Japan). Two types of compression tests, i.e., the conventional compression test and the parallel round bar compression (PRBC) test, were carried out for as-annealed and ECAPed materials as shown Figure 1. The conventional compression tests were performed in order to investigate mainly the strain-hardening behavior and strain-rate sensitivity with no interference of necking. Cylindrical billets of $4 \mathrm{~mm}$ in diameter and $8 \mathrm{~mm}$ in length were machined using a lathe from as-annealed and ECAPed materials and compressed at a speed of $0.5,2.0$ and $5.0 \mathrm{~mm} / \mathrm{min}$ (Figure 1a). In order to reduce the effect of the friction between the billets and plungers, $\mathrm{MoS}_{2}$ lubricant was used. Since the purpose of the compression test is not to evaluate ductility, the tests were interrupted when the load reached a certain level. In the PRBC test (Figure 1b), a sample plate was compressed between two parallel cylindrical bars in order to evaluate the compressive ductility of materials. The strain to fracture is defined by the strain to failure as $\varepsilon=\ln \left(t_{\mathrm{o}} / t_{f}\right)$, where $t_{\mathrm{o}}$ is the initial thickness and $t_{f}$ is the final thickness. The aim of the PRBC test is to evaluate the compressive ductility and the final thickness as well. Since there is no universal method to evaluate the compressive ductility, especially in a very high strain range, this method was designed by the present authors. The conventional compression test as shown in Figure 1a does not meet this purpose, because compressive load becomes very high with increasing contact area, which would become very large when the thickness becomes the order of grain size. For example, when the initial thickness is $4 \mathrm{~mm}$, then the compressive load becomes at least 400 times higher than the initial load when the final thickness becomes as small as $40 \mu \mathrm{m}$, which is not an unrealistic value, as shown later.

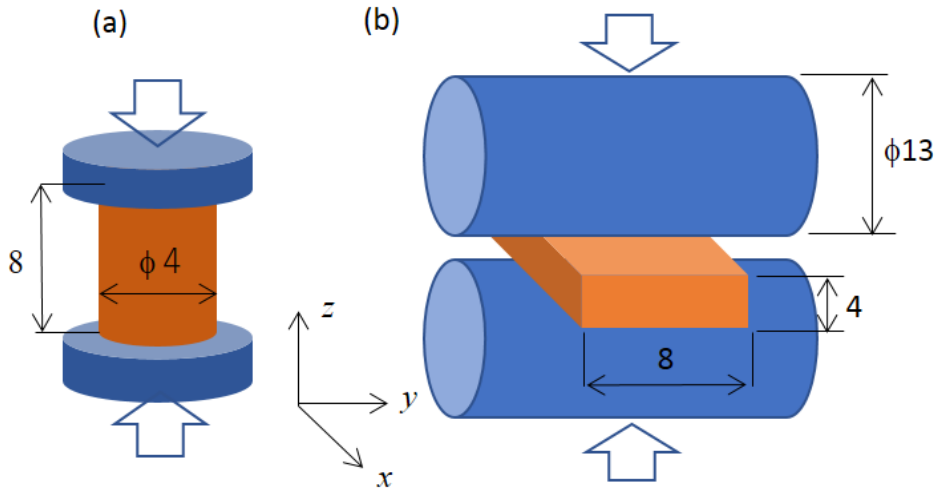

Figure 1. Schematic diagram of (a) compression test and (b) parallel round-bar compression (PRBC) test (unit: $\mathrm{mm}$ ). In the PRBC tests, a sample plate was compressed by two parallel cylindrical bars.

The maximum load reaches about $8000 \mathrm{kN}$ when yield stress is $400 \mathrm{MPa}$ and is well over the capacity of the general universal mechanical testing machine. If the materials exhibit strain hardening, the compressive load increases further. Note that the stress state of the PRBC test becomes essentially the same as that of the compression test when the thickness of a sample becomes extremely small relative to the radius of the cylindrical bar. The initial stress triaxiality may be between -0.33 and 0 , and then it may decrease and become close to that of the compression tests when the thickness becomes extremely small relative to the cylinder radius. Compression was carried out in a step-by-step manner until a crack was detected along the contact area. When a crack was detected, the specimen was separated for further evaluation of the thickness and fracture surface (Figure 2). Microstructures were observed mainly via scanning electron microscopy (SEM, JEOL, Tokyo, Japan) with a field-emission gun (FE-SEM, JSM7000) equipped with an electron-backscattered diffraction (EBSD) detector. Observation 
was carried out on the plane from a transverse direction, which is normal to both the extrusion and intrusion direction of ECAP.

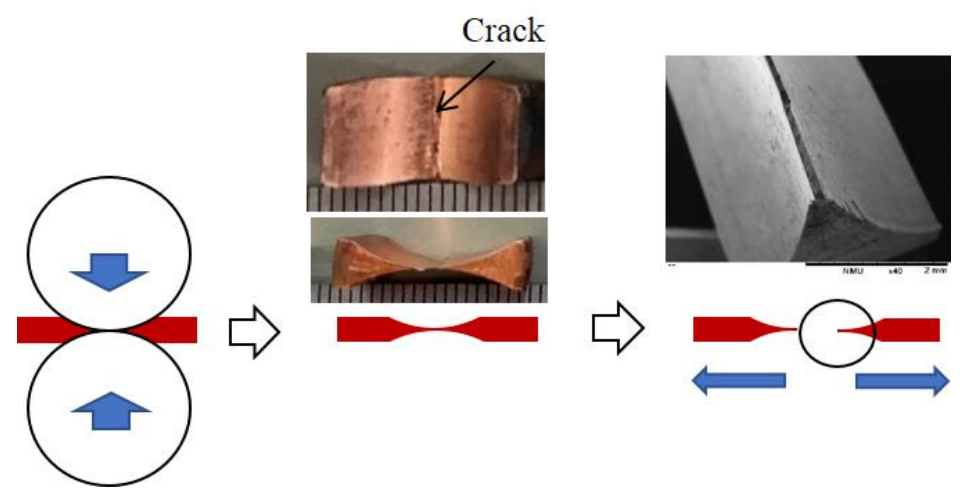

Figure 2. Schematic diagram showing the procedure of PRBC tests and evaluation of the final thickness and fracture surface.

Parallel numerical simulations of the round-bar compression tests were carried out using commercial finite element package ABAQUS (6.14, Dassault Systems, RI, USA) in order to predict stress distribution and the stress triaxiality evolution at the fracture locations. Simulations are performed with 3D models. The specimen is meshed with 3D (C3D8) elements of ABAQUS, and the dies are modeled as rigid bodies. Only half of the specimen is solved utilizing the symmetry of the problem with appropriate symmetry boundary conditions. Note that the mesh is refined at the specimen-die contact surface. The upper die is pressed downwards (in the $y$-direction) to the specimen while the lateral displacement is fixed (in $x$ and $z$ directions). The lower die is fixed in all directions. Between the die surfaces and the specimen, both normal and tangential contact is defined. Different tangential friction coefficients are investigated with the penalty contact and the frictionless case is solved as well. Simulations are performed quasi statically using the implicit solver ABAQUS/Standard with automatic step size with a maximum step size of 0.01 and total simulation time of 1 . The non-linear geometry option is also employed. Young's modulus is $120 \mathrm{GPa}$ and Poisson's ratio is 0.34, which are typical values for copper [32]. Perfect plastic behavior is assumed considering the limited strain hardening of UFG copper. Yield stress is taken as $370 \mathrm{MPa}$, which is extracted from compression test of UFG copper with eight passes. As an output, stress triaxiality is introduced to the ABAQUS with a user-defined output variable subroutine UVARM and results are extracted from three critical positions (see Figure 3) where there is a higher possibility of failure.

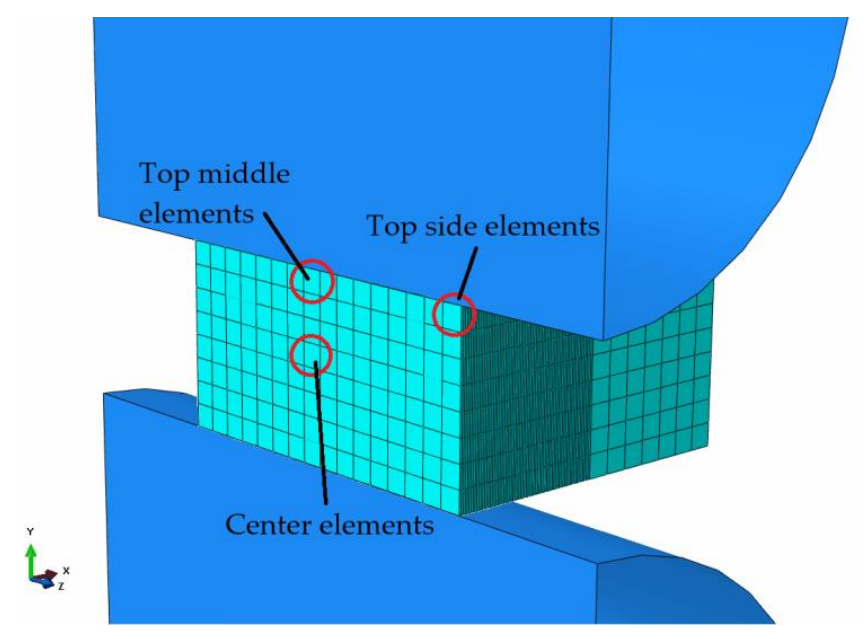

Figure 3. Finite element method (FEM) model of PRBC test and the reference position of calculation of stress triaxiality. 


\section{Results and Discussion}

\subsection{Microstructures and Tensile Properties of Ultrafine Grained Copper}

Figure 4 shows orientation image maps after annealing and ECAP for up to eight passes. Initial microstructures are primarily equiaxial grains with an average grain size of $80 \mu \mathrm{m}$. After one and two passes of ECAP, grains were severely elongated along the macroscopic shear plane of ECAP, and grain boundaries were arranged parallel to the shear plane of ECAP [12]. After eight passes, the microstructure was back to an equiaxial grain structure with a reduced grain size of $0.3 \mu \mathrm{m}$ and weak texture. Figure 5 shows true stress-true strain curves obtained using tensile tests. Typical to copper, the as-annealed sample has low yield stress but exhibited pronounced strain hardening and high elongation to fracture. On the other hand, the ECAPed samples exhibited higher yield stress, and their peak stress increased with increasing passes because of grain fragmentation and high dislocation density. While the as-annealed sample exhibited pronounced strain hardening, ECAPed samples showed much less strain hardening, and after two passes and more, true stress starts to decrease with the onset of plastic deformation. It is important to note that the elongation to failure decreased drastically after one pass, but with increasing passes, it holds almost the same elongation until eight passes in spite of higher flow stress. As discussed later, increasing post-necking local elongation seems to compensate for the uniform elongation, which decreases via the loss of strain hardening. Figure 6 shows the macroscopic appearance of samples after tensile tests. The as-annealed and eight-pass samples show a typical cup-and-cone fracture, while the samples after one to four passes show fracture using shearing mode. This difference may reflect the anisotropy of the microstructure. As shown in Figure 4, high-angle grain boundaries (HAGBs) aligned along the macroscopic shear plane of the final ECAP pass in the samples after one to eight passes, while HAGBs became equiaxial and isotropic after zero and eight passes. The microscopic process of ductile fracture, i.e., void nucleation and growth, could be initiated by the shear stress at these aligned grain boundaries [33]. The local area reduction at the necking decreased with increasing passes, but it is still observable after eight passes, reflecting the certain level of post-necking local elongation is preserved even after eight passes. The apparent decreasing of true stress after yielding may partly be due to the necking, not necessarily the physical softening. Figure 7 shows the fracture surface at the center part of the surface after the tensile tests. All the samples show a typical dimple surface, and there is essentially no featured difference among these samples. After eight passes, UFG samples fractured in the ductile manner at the microscopic scale, i.e., void nucleation and subsequent connection, reflecting high post-necking elongation.
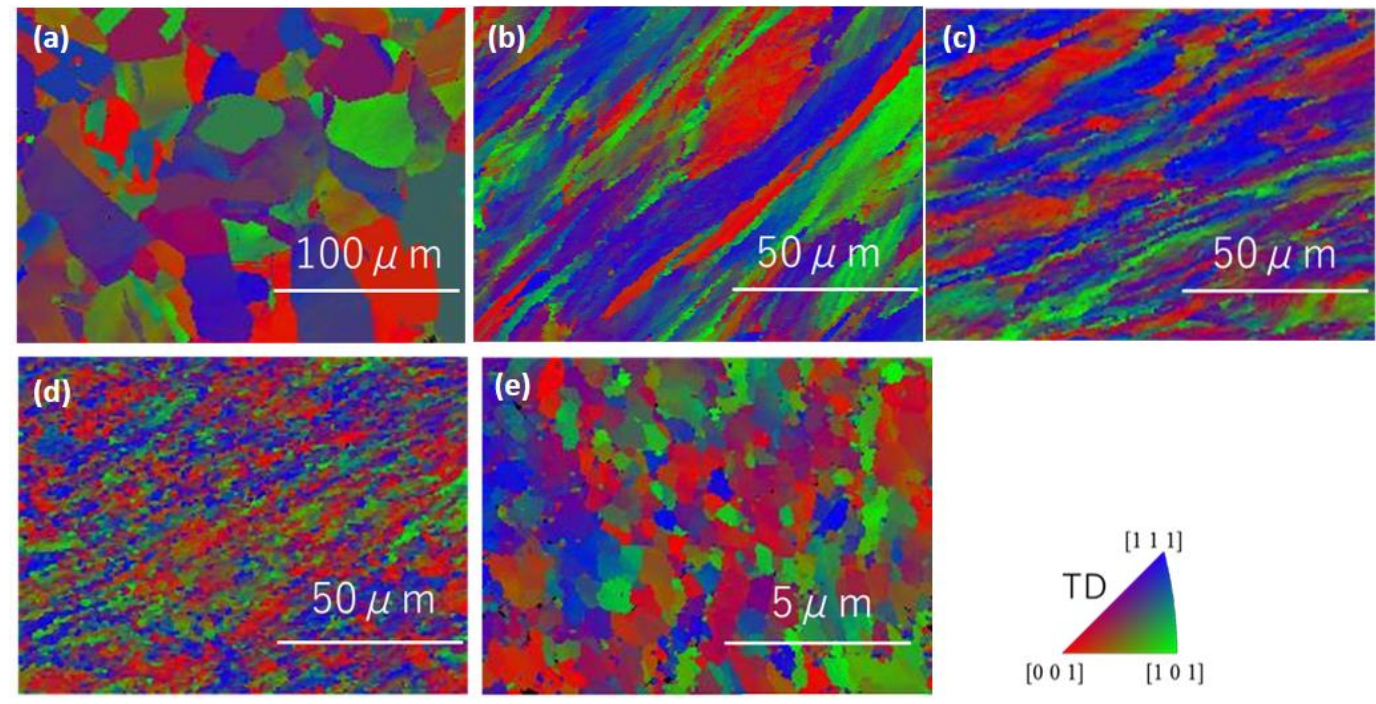

Figure 4. Orientation image maps of (a) as-annealed, (b) one pass, (c) two passes, (d) four passes, and (e) eight passes of equal-channel angular pressing (ECAP). 


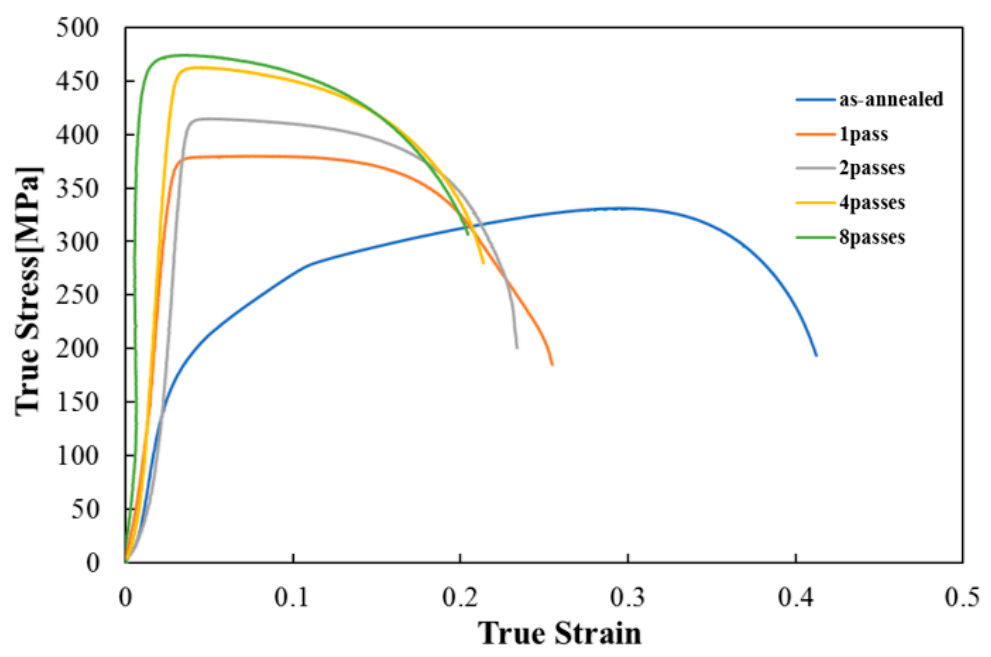

Figure 5. True stress-true strain curves after ECAP.
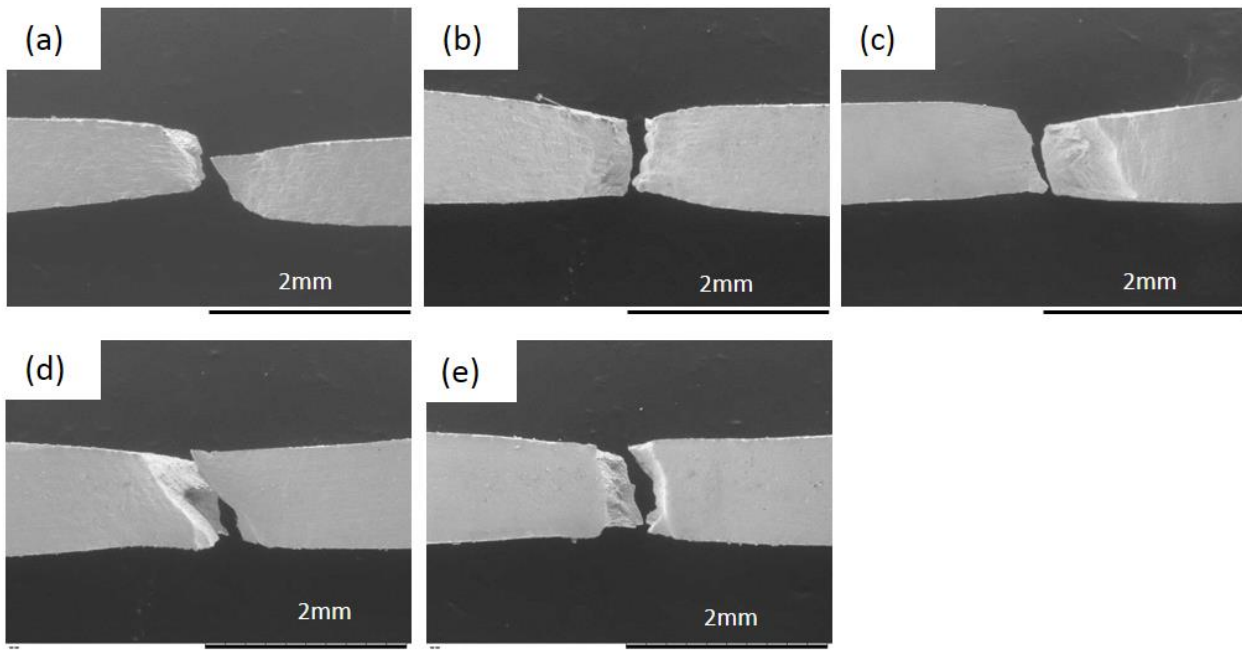

Figure 6. Macroscopic appearances of specimens after tensile tests, (a) as-annealed, (b) one, (c) two, (d) four, and (e) eight passes.
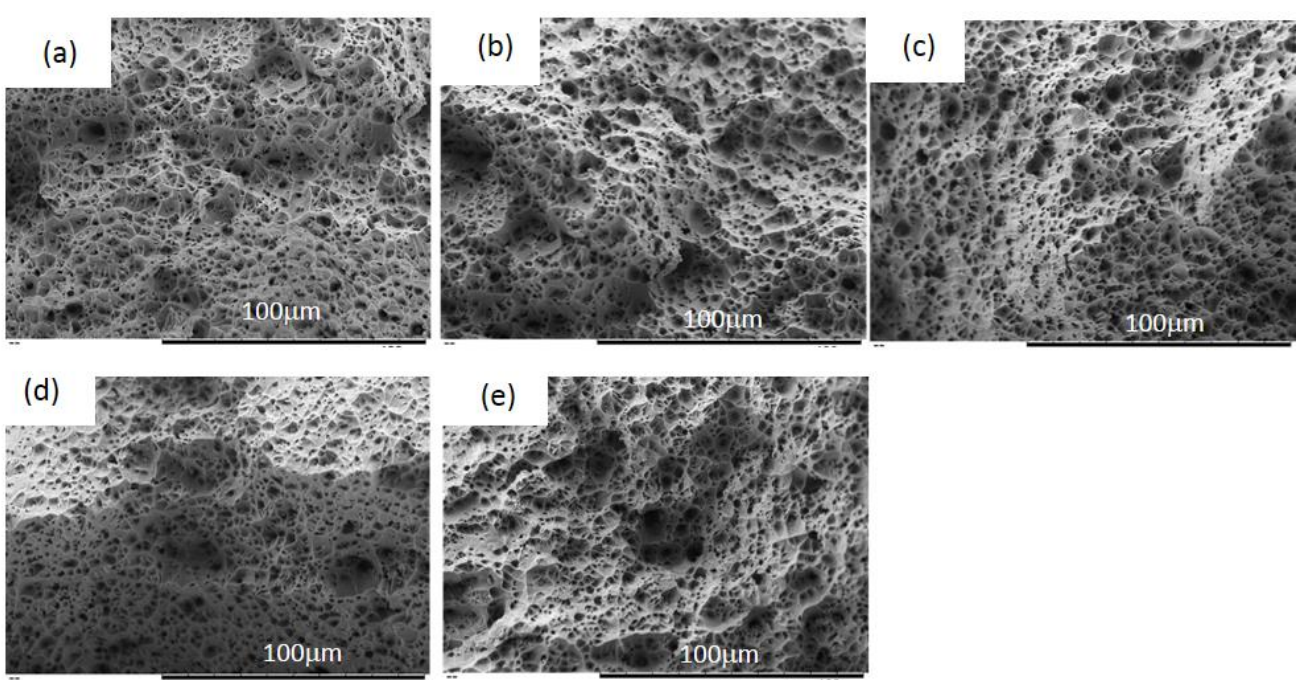

Figure 7. Fracture surface of specimens after tensile tests, (a) as-annealed, (b) one pass, (c) two passes, (d) four passes, and (e) eight passes of ECAP. 


\subsection{Compression Test and Parallel Round-Bar Compression Test}

In order to examine the strain hardening behavior and strain-rate sensitivity with no interference of necking, conventional compression (upsetting) tests were performed (Figure 1a). Figure 8 shows true stress-true strain curves of the conventional compression tests. Contrary to the tensile tests, true stress increased gradually upon yielding and exhibited a small level of strain hardening in all samples. The degree of strain hardening decreased with an increasing number of ECAP passes. Note that there is a deflection in all curves at a strain between 0.4 to 0.6 , and this was caused by superimposing of the upper and lower dead metals zones, which is the zone constrained by the friction and is hard to deform [32]. It has been reported that microstructures such as grain size, the fraction of grain boundaries becomes saturated after enough plastic strain is imposed using SPD [34], and the critical strain required for the saturation depends on the materials. Generally, materials with higher strength, higher melting temperature, and lower stacking energy and alloys with higher composition tend to require higher strain for the steady-state of the microstructure [35-38]. For example, pure aluminum shows the steady-state of an UFG structure after six passes of ECAP [36], whereas pure copper requires more than eight passes [38]. Therefore, in the present study, there is a possibility that the microstructure did not reach steady-state or form a complete ultrafine grain structure. In other words, microstructures may have residual dislocations, a high proportion of subgrain/cell boundaries, which would decrease with more additional ECAP passes, forming a more complete UFG structure with predominant high-angle grain boundaries. Unfortunately, further pressing was not possible because the sample became too short for additional pressing. Figure 9 shows the orientation maps after the compression tests. Grain structures become flattened in as-annealed and pressed samples for one to four passes. Compared with the other samples, the UFG samples exhibited little change in grain structures and retained equiaxial grains. It is clear if one compares the change of grain structures in as-annealed and UFG samples that the grain shapes in the former samples become compressed corresponding to sample compression whereas the shape change of grains is smaller in the latter. These differences in grain shape change can be attributed to the difference in deformation mechanism. Dislocation slip inside grains is the main deformation mechanism in as-annealed samples and those after one to four passes, whereas grain boundary-mediated plasticity (GBMP) accompanying grain boundary sliding and grain rotation is the main mechanism in UFG copper [11,39]. In the present study, both the conventional and GBMP mechanism may operate in UFG copper, because of incomplete or unsaturated UFG structure, and this can explain some strain hardening observed in the compression tests. The effect of strain rate on the flow stress of ECAPed samples (eight passes) is shown in Figure 10. Strain rate sensitivity, $m$, as defined by $m=\ln \left(\sigma_{2} / \sigma_{1}\right) / \ln \left(\varepsilon_{2} / \varepsilon_{1}\right)$, is between 0.03 to 0.1 and is consistent with a previous study by Dalla Torre at al. [40], and it is well below 0.5 , which is a prerequisite for exhibiting superplastic deformation of Cu-alloys [41,42]. Therefore, in the present samples after eight passes of ECAP, deformation was occurring predominantly via GBMP, but the effect of the superplastic viscous nature of deformation is very limited, as was argued in a study on a very high extensibility of nanocrystalline copper [20]. Figure 11 shows fracture surfaces after the PRBC tests. Ductile cracks mostly initiated at the edge part of the plane, and observation was focused on these parts. Overall, the effect of ECAP passes on the ultimate thickness to fracture is small. However, UFG copper can be compressed to the thickness of $0.03 \mu \mathrm{m}$ from the initial thickness $(4.0 \mathrm{~mm})$ until fracture. Surprisingly, the final thickness to fracture is comparable or even smaller than that of as-annealed and deformed samples (Table 1). Typical dimple surfaces were observed in as-annealed and deformed samples. However, in UFG copper, a careful observation finds some smooth segmented surface areas inside the fracture surface as indicated by the dotted line in Figure 11e. This smooth surface corresponds with grain size and may appear as a result of shear separation along grain boundaries. 


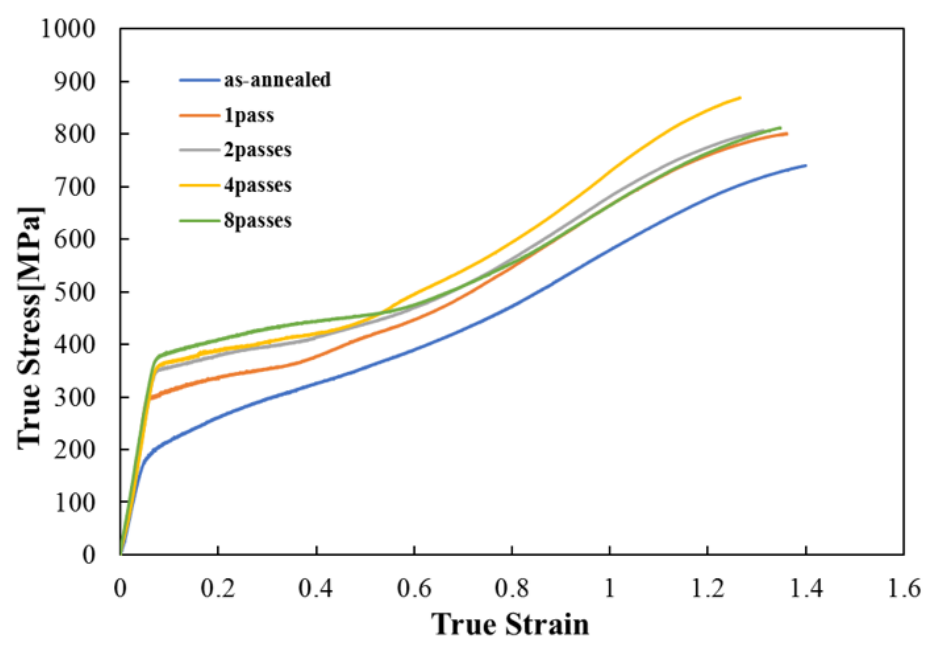

Figure 8. True stress-true strain curves of the conventional compression tests.
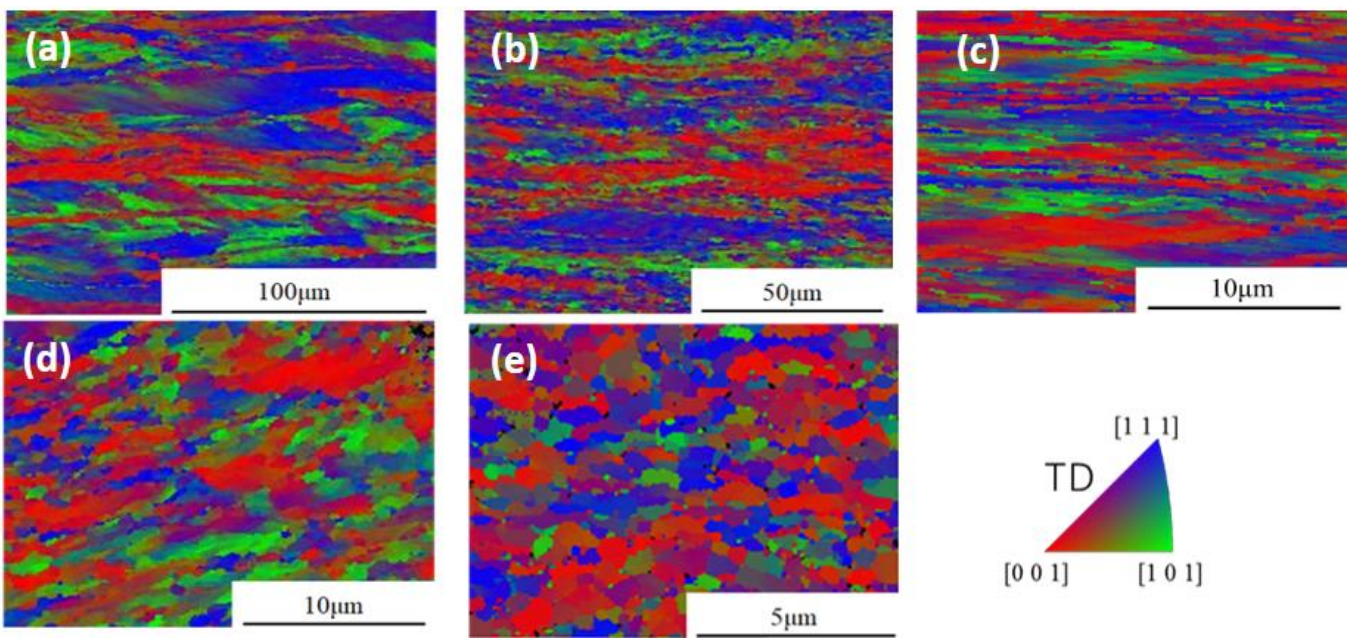

Figure 9. Orientation image maps after compression tests, (a) as-annealed, (b) one pass, (c) two passes, (d) four passes, and (e) eight passes of ECAP.

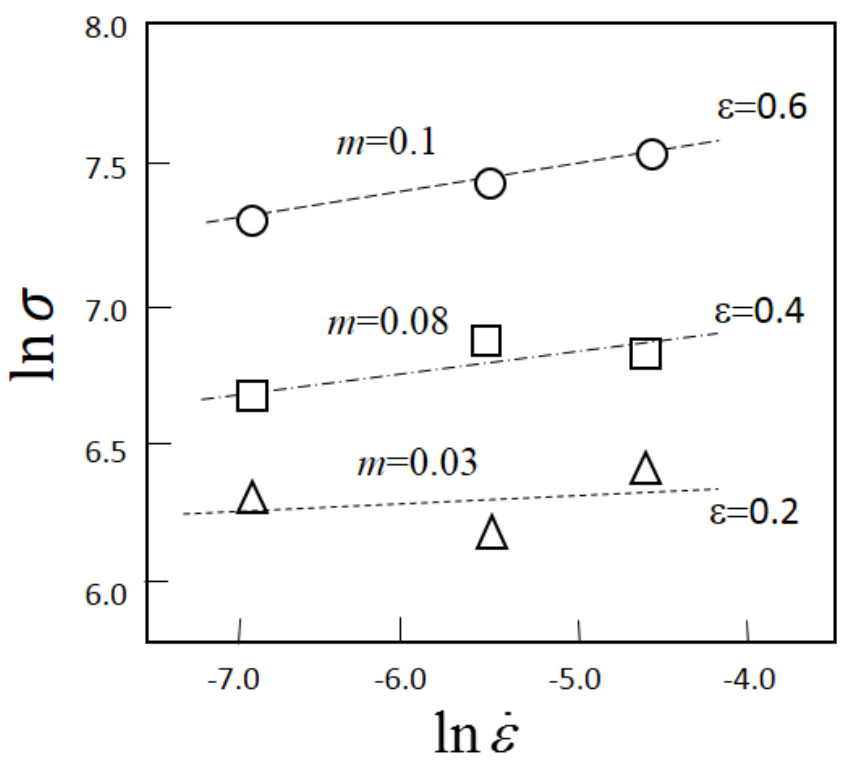

Figure 10. Effect of strain rate on the flow stress of ultrafine grained (UFG) copper press using ECAP for eight passes in the conventional compression tests. Flow stress is at a strain of 0.2, 0.4, and 0.6. 

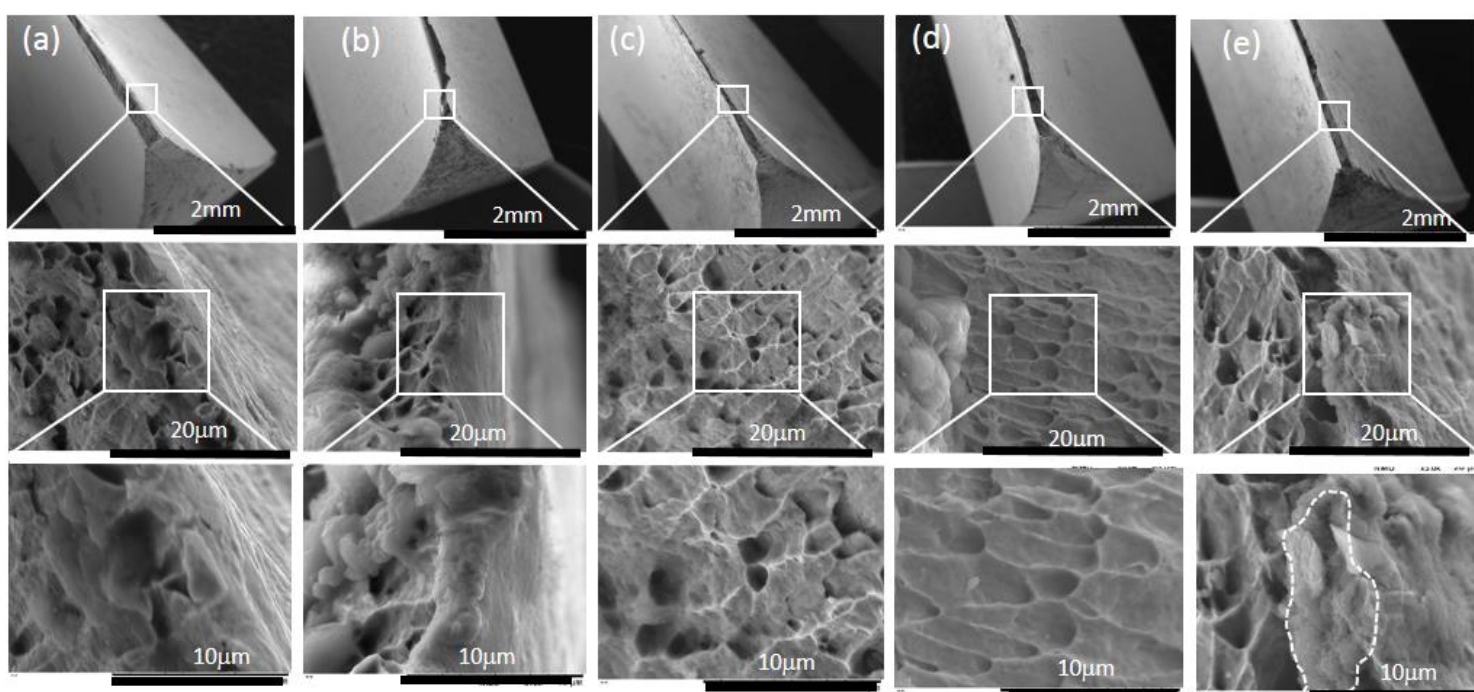
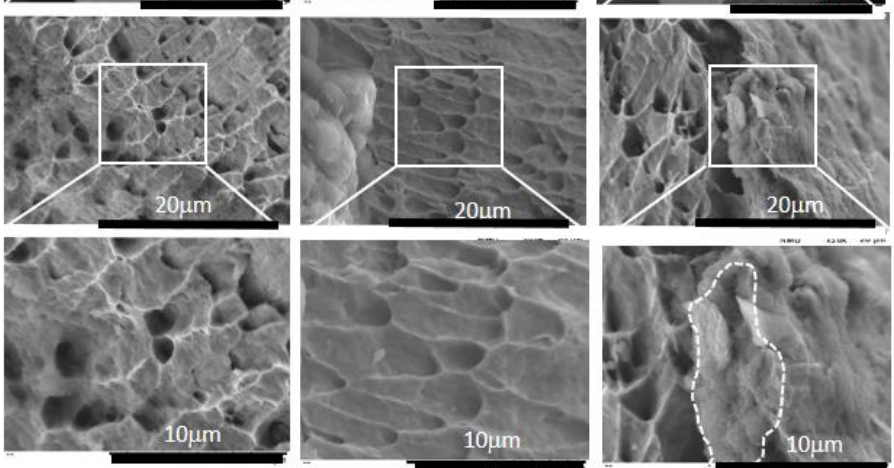

Figure 11. Macroscopic appearance and fracture surfaces after the parallel round bar compression tests, (a) as-annealed, (b) one pass, (c) two passes, (d) four passes, and (e) eight passes.

Table 1. The initial and final thickness of the samples and strain to failure in PRBC tests.

\begin{tabular}{cccc}
\hline Pass Number & $\boldsymbol{t}_{\mathbf{o}}(\mathbf{m m})$ & $\boldsymbol{t}_{f}(\mathbf{m m})$ & $\varepsilon_{f}$ \\
\hline 0 & 4.0 & 0.25 & 2.80 \\
1 & 4.0 & 0.025 & 5.07 \\
2 & 4.0 & 0.03 & 4.89 \\
4 & 4.0 & 0.035 & 4.74 \\
8 & 4.0 & 0.030 & 4.89 \\
\hline
\end{tabular}

\subsection{Finite Element Method Simulation}

Figure 12 shows the variation of the stress triaxiality, $T\left(=\sigma_{\mathrm{m}} / \sigma_{\mathrm{eq}}\right)$, during PRBC tests, computed using ABAQUS. The stress triaxiality overall changes anomalously with increasing round-bar displacement, and they are different at different locations. However, the average stress triaxiality of the top side element, where the ductile crack initiation occurred, increases rapidly at the initial displacement to nearly 0 , then increases gradually with a very small rate and stays larger than 0 at a larger strain range. According to Bao [18], shear fracture becomes the predominant mode when stress triaxiality is larger than $-1 / 3$ and up to about 0 , and no fracture is supposed to occur at shear triaxiality lower than $-1 / 3$ [18]. Therefore, FEM validated the location of the ductile crack formation and predicted that the ductile crack was initiated by the shear mode. It is indicated that the present method with appropriate dimensions of the round-bar and the sample and low friction enable us to evaluate the ductility at a very high strain range. This is not achieved using the conventional compression (upsetting) tests where the samples can deform with no fracture until very high compressive strain and high load, which may become over the maximum load of the machine.

The high or comparable malleability of UFG materials can be explained by the high tolerance to void formation by shear mode, and this is due to high strain accommodation at non-equilibrium grain boundaries and grain boundary sliding. As described in the compression test, the UFG structure after eight passes may still be incomplete, as suggested by a residual strain hardening, and it may have limited the malleability, which is otherwise able to reduce to as thin as grain size. Lu et al. reported the extremely high extensibility of nanocrystalline copper at room temperature, and this was attributed to superplastic deformation [20]. However, it is suggested that high tolerant strain to void nucleation and growth which is achieved in UFG materials under a compressive stress state is a more dominant factor than the viscous nature (high m-value) of superplastic materials. 

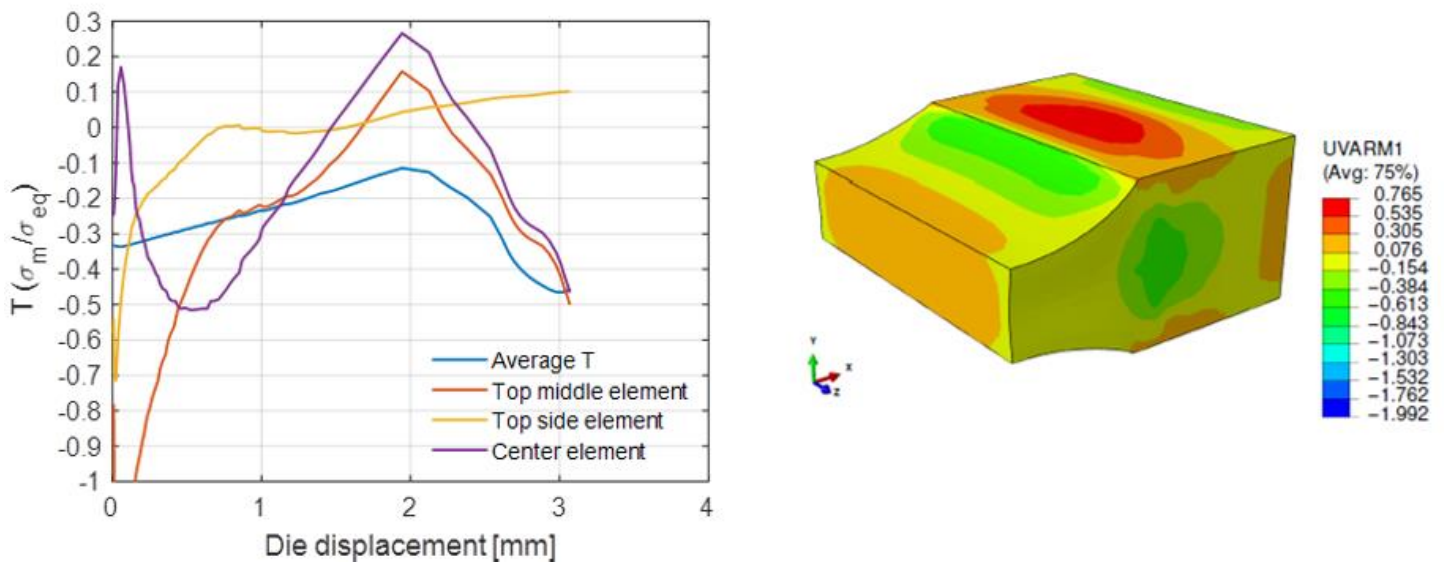

Figure 12. FEM result of variation of the stress triaxiality $T\left(=\sigma_{\mathrm{m}} / \sigma_{\mathrm{eq}}\right)$ during the PRBC test and the stress triaxiality distribution for the displacement of $2 \mathrm{~mm}$.

\section{Conclusions}

The effect of severe plastic deformation via ECAP on the compressive ductility of pure copper was investigated. Compressive ductility was evaluated by compressing the sample between two parallel round bars, so that ductility at a very high strain range could be achieved at an appropriate stress state. The following conclusions are reached.

1. Flow stress during tensile and compression tests increased with the increasing number of ECAP passes, up to eight passes. Strain-hardening capability was reduced with increasing ECAP passes. Elongation to failure was greatly reduced after one pass, but further reduction with additional passes was small until eight passes. Reduced uniform elongation due to reduced strain hardening with increasing number of passes was compensated by increasing post-necking local elongation.

2. During compression tests, grain shape change was very small in UFG copper pressed using eight passes compared with as-annealed and other (one to four passes) samples. This confirms that the deformation mechanism is grain boundary-mediated plasticity accompanying grain boundary sliding and rotation, which has been suggested to operate in UFG materials. This may explain the limited strain hardening observed in the compression tests.

3. Superior or comparable compressive ductility of UFG copper to as-annealed copper was revealed in the compression tests using the parallel round bars. UFG materials that are deformed by the grain boundary-mediated plasticity with no or limited strain hardening have high tolerance to damage accumulation and higher malleability under a preferable stress state for shear deformation. The viscous superplastic nature of a high $\mathrm{m}$-value is not necessarily involved in the high compressive ductility.

Author Contributions: Conceptualization, H.M. and T.T.; methodology, M.A.; computation, T.Y. and C.E.; investigation, M.A. and M.Y.; writing—original draft preparation, H.M. and T.Y.; writing—review and editing, H.M. and T.Y.; supervision, H.M.; project administration, H.M.; funding acquisition, H.M. All authors have read and agreed to the published version of the manuscript.

Funding: This work was supported by JSPS KAKENHI, grant numbers JP18K04783 and JP19K04079.

Conflicts of Interest: The authors declare no conflict of interest. 


\section{References}

1. Valiev, R.; Islamgaliev, R.; Alexandrov, I. Bulk nanostructured materials from severe plastic deformation. Prog. Mater. Sci. 2000, 45, 103-189. [CrossRef]

2. Miyamoto, H.; Erb, U.; Koyama, T.; Mimaki, T.; Vinogradov, A.; Hashimoto, S. Microstructure and texture development of copper single crystals deformed by equal-channel angular pressing. Philos. Mag. Lett. 2004, 84, 235-243. [CrossRef]

3. Miyamoto, H.; Fushimi, J.; Mimaki, T.; Vinogradov, A.; Hashimoto, S. The Effect of the Initial Orientation on Microstructure Development of Copper Single Crystals Subjected to Equal-Channel Angular Pressing. Mater. Sci. Forum 2006, 503, 799-804. [CrossRef]

4. Zhao, Y.-H.; Bingert, J.F.; Liao, X.-Z.; Cui, B.-Z.; Han, K.; Sergueeva, A.V.; Mukherjee, A.K.; Valiev, R.Z.; Langdon, T.G.; Zhu, Y.T. Simultaneously Increasing the Ductility and Strength of Ultra-Fine-Grained Pure Copper. Adv. Mater. 2006, 18, 2949-2953. [CrossRef]

5. Miyamoto, H.; Harada, K.; Mimaki, T.; Vinogradov, A.; Hashimoto, S. Corrosion of ultra-fine grained copper fabricated by equal-channel angular pressing. Corros. Sci. 2008, 50, 1215-1220. [CrossRef]

6. Miyamoto, H. Corrosion of Ultrafine Grained Materials by Severe Plastic Deformation, an Overview. Mater. Trans. 2016, 57, 559-572. [CrossRef]

7. Yalçinkaya, T.; Şimşek, Ü.; Miyamoto, H.; Yuasa, M. Numerical Analysis of a New Nonlinear Twist Extrusion Process. Metals 2019, 9, 513. [CrossRef]

8. Bagherpour, E.; Qods, F.; Ebrahimi, R.; Miyamoto, H. Nanostructured pure copper fabricated by simple shear extrusion (SSE): A correlation between microstructure and tensile properties. Mater. Sci. Eng. A 2017, 679, 465-475. [CrossRef]

9. Łyszkowski, R.; Łazińska, M.; Zasada, D. The Influence of a Cross-Channel Extrusion Process on the Microstructure and Properties of Copper. Materials 2019, 12, 3995. [CrossRef]

10. Orlowska, M.; Olejnik, L.; Lewandowska, M. The influence of an ECAP-based deformation process on the microstructure and properties of electrolytic tough pitch copper. J. Mater. Sci. 2017, 53, 3862-3875. [CrossRef]

11. Valiev, R.Z.; Alexandrov, I.V.; Zhu, Y.T.; Lowe, T.C. Paradox of strength and ductility in metals processed by severe plastic deformation. J. Mater. Res. 2002, 17, 5-8. [CrossRef]

12. Ma, E. Eight routes to improve the tensile ductility of bulk nanostructured metals and alloys. JOM J. Miner. Met. Mater. Soc. 2006, 58, 49-53. [CrossRef]

13. Koch, C. Optimization of strength and ductility in nanocrystalline and ultrafine grained metals. Scr. Mater. 2003, 49, 657-662. [CrossRef]

14. Koch, C.; Morris, D.; Lu, K.; Inoue, A. Ductility of Nanostructured Materials. MRS Bull. 1999, 24, 54-58. [CrossRef]

15. Kumar, P.; Kawasaki, M.; Langdon, T.G. Review: Overcoming the paradox of strength and ductility in ultrafine-grained materials at low temperatures. J. Mater. Sci. 2016, 51, 7-18. [CrossRef]

16. Considere, A. Memoire sur l'emploi du fer et de l'acier dans les constructions. Ann. Ponts Chaussees 1885, 9, 574-575.

17. Wang, Y.M.; Ma, E.; Chen, M.W. Enhanced tensile ductility and toughness in nanostructured Cu. Appl. Phys. Lett. 2002, 80, 2395-2397. [CrossRef]

18. Bao, Y.; Wierzbicki, T. On fracture locus in the equivalent strain and stress triaxiality space. Int. J. Mech. Sci. 2004, 46, 81-98. [CrossRef]

19. Hoseini, S.H.; Khalilpourazary, S.; Zadshakoyan, M. Fracture Behavior of Annealed and Equal Channel Angular Pressed Copper: An Experimental Study. J. Mater. Eng. Perform. 2020, 29, 975-986. [CrossRef]

20. Lu, L.; Sui, M.L.; Lu, K. Superplastic Extensibility of Nanocrystalline Copper at Room Temperature. Science 2000, 287, 1463-1466. [CrossRef]

21. Talebanpour, B.; Ebrahimi, R.; Janghorban, K. Microstructural and mechanical properties of commercially pure aluminum subjected to Dual Equal Channel Lateral Extrusion. Mater. Sci. Eng. A 2009, 527, 141-145. [CrossRef]

22. Sabirov, I.; Barnett, M.; Estrin, Y.; Hodgson, P. The effect of strain rate on the deformation mechanisms and the strain rate sensitivity of an ultra-fine-grained Al alloy. Scr. Mater. 2009, 61, 181-184. [CrossRef]

23. El-Danaf, E.; Soliman, M.; Almajid, A.; El-Rayes, M. Enhancement of mechanical properties and grain size refinement of commercial purity aluminum 1050 processed by ECAP. Mater. Sci. Eng. A 2007, 458, 226-234. [CrossRef] 
24. Blum, W.; Li, Y.; Zhang, Y.; Wang, J. Deformation resistance in the transition from coarse-grained to ultrafine-grained $\mathrm{Cu}$ by severe plastic deformation up to 24 passes of ECAP. Mater. Sci. Eng. A 2011, 528, 8621-8627. [CrossRef]

25. El-Danaf, E.A. Mechanical properties and microstructure evolution of 1050 aluminum severely deformed by ECAP to 16 passes. Mater. Sci. Eng. A 2008, 487, 189-200. [CrossRef]

26. Hockauf, M.; Meyer, L.W. Work-hardening stages of AA1070 and AA6060 after severe plastic deformation. J. Mater. Sci. 2010, 45, 4778-4789. [CrossRef]

27. May, J.; Hoppel, H.W.; Goken, M. Strain rate sensitivity of ultrafine-grained aluminum processed by severe plastic deformation. Scr. Mater. 2005, 53, 189-194. [CrossRef]

28. Valiev, R.; Kozlov, E.; Ivanov, Y.; Lian, J.; Nazarov, A.; Baudelet, B. Deformation behaviour of ultra-fine-grained copper. Acta Met. Mater. 1994, 42, 2467-2475. [CrossRef]

29. Han, B.Q.; Mohamed, F.A.; Lavernia, E.J. Mechanical properties of iron processed by severe plastic deformation. Met. Mater. Trans. A 2003, 34, 71-83. [CrossRef]

30. Reihanian, M.; Ebrahimi, R.; Tsuji, N.; Moshksar, M. Analysis of the mechanical properties and deformation behavior of nanostructured commercially pure Al processed by equal channel angular pressing (ECAP). Mater. Sci. Eng. A 2008, 473, 189-194. [CrossRef]

31. Long, F.-W.; Jiang, Q.-W.; Xiao, L.; Li, X.-W. Compressive Deformation Behaviors of Coarse- and Ultrafine-Grained Pure Titanium at Different Temperatures: A Comparative Study. Mater. Trans. 2011, 52, 1617-1622. [CrossRef]

32. Meyers, M.A. Mechanical Behavior of Materials, 2nd ed.; Cambridge University Press: Cambridge, UK, 2009.

33. Fleck, N.A.; Hutchinson, J.W.; Bilby, B.A. Void growth in shear. Proc. R. Soc. Lond. A Math. Phys. Sci. 1986, 407, 435-458.

34. Xu, C.; Furukawa, M.; Horita, Z.; Langdon, T.G. The evolution of homogeneity and grain refinement during equal-channel angular pressing: A model for grain refinement in ECAP. Mater. Sci. Eng. A 2005, 398, 66-76. [CrossRef]

35. Iwahashi, Y.; Horita, Z.; Nemoto, M.; Langdon, T.G. Factors influencing the equilibrium grain size in equal-channel angular pressing: Role of Mg additions to aluminum. Met. Mater. Trans. A 1998, 29, 2503-2510. [CrossRef]

36. Horita, Z.; Fujinami, T.; Nemoto, M.; Langdon, T.G. Equal-channel angular pressing of commercial aluminum alloys: Grain refinement, thermal stability and tensile properties. Met. Mater. Trans. A 2000, 31, 691-701. [CrossRef]

37. Huang, C.-X.; Hu, W.; Yang, G.; Zhang, Z.; Wu, S.; Wang, Q.; Gottstein, G. The effect of stacking fault energy on equilibrium grain size and tensile properties of nanostructured copper and copper-aluminum alloys processed by equal channel angular pressing. Mater. Sci. Eng. A 2012, 556, 638-647. [CrossRef]

38. Torre, F.D.; Lapovok, R.; Sandlin, J.; Thomson, P.; Davies, C.; Pereloma, E. Microstructures and properties of copper processed by equal channel angular extrusion for 1-16 passes. Acta Mater. 2004, 52, 4819-4832. [CrossRef]

39. Chinh, N.Q.; Szommer, P.; Horita, Z.; Langdon, T.G. Experimental Evidence for Grain-Boundary Sliding in Ultrafine-Grained Aluminum Processed by Severe Plastic Deformation. Adv. Mater. 2006, 18, 34-39. [CrossRef]

40. Torre, F.D.; Pereloma, E.; Davies, C. Strain hardening behaviour and deformation kinetics of Cu deformed by equal channel angular extrusion from 1 to 16 passes. Acta Mater. 2006, 54, 1135-1146. [CrossRef]

41. Nieh, T.G.; Wadsworth, J.; Sherby, O.D. Superplasticity in Metals and Ceramics; Cambridge University Press (CUP): Cambridge, UK, 1997; pp. 1-125.

42. Łyszkowski, R.; Bystrzycki, J. Hot deformation and processing maps of a Fe-Al intermetallic alloy. Mater. Charact. 2014, 96, 196-205. [CrossRef]

Publisher's Note: MDPI stays neutral with regard to jurisdictional claims in published maps and institutional affiliations. 